\title{
Synthesis of Nanoporous Carbohydrate Metal-Organic Framework and Encapsulation of Acetaldehyde
}

$5 \quad{ }^{1}$ Department of Agricultural Engineering, College of Food and Agricultural Sciences, King Saud 6 University, P.O. Box 2460, Riyadh 11451, Saudi Arabia

$7{ }^{2}$ Industrial Technology and Packaging, California Polytechnic State University, San Luis

8 Obispo, CA 93407, USA

$9 \quad{ }^{3}$ Department of Nutrition and Food Sciences, American University of Beirut, P.O. Box 11-0236

10 Riad El Solh, Beirut 1107-2020, Lebanon

$11{ }^{4}$ School of Packaging, Michigan State University, East Lansing, MI 48824, USA

12

13

14

15

16

17

18

19

20

21

22

23

24 "Corresponding authors: E: akathuri@calpoly.edu; aurasraf@msu.edu; P: 805-756-2944, 517-

$25 \quad 432-3254$ 
27 Gamma cyclodextrin (CD) metal organic frameworks (CDMOFs) were synthesized by 28 coordinating $\gamma$-CDs with potassium hydroxide $(\mathrm{KOH})$, referred hereafter as CDMOF-a, and 29 potassium benzoate $\left(\mathrm{C}_{7} \mathrm{H}_{5} \mathrm{KO}_{2}\right)$, denoted as CDMOF-b. The obtained CDMOF structures were 30 characterized using nitrogen sorption isotherm, thermo-gravimetric analysis (TGA), X-ray 31 diffraction (XRD), and scanning electron microscopy (SEM). High surface areas were achieved

32 by the $\gamma$-CD based MOF structures where the Langmuir specific surface areas (SSA) of 33 CDMOF-a and CDMOF-b were determined as $1,376 \mathrm{~m}^{2} \cdot \mathrm{g}^{-1}$ and $607 \mathrm{~m}^{2} \cdot \mathrm{g}^{-1}$; respectively. The 34 dehydrated CDMOF structures demonstrated good thermal stability up to $250{ }^{\circ} \mathrm{C}$ as observed by 35 the TGA studies. XRD results for CDMOF-a and CDMOF-b reveal a body centered-cubic 36 (BCC) and trigonal crystal system; respectively. Due to its accessible porous structure and high 37 surface area, acetaldehyde was successfully encapsulated in CDMOF-b. During the release 38 kinetic studies, we observed peak release of $53 \mu \mathrm{g}$ of acetaldehyde per $\mathrm{g}$ of CDMOF-b, which 39 was 100 times greater than previously reported encapsulation in $\beta$-CD. However, aldol 40 condensation reaction occurred during encapsulation of acetaldehyde into CDMOF-a. This 41 research work demonstrates the potential to encapsulate volatile organic compounds in CDMOF$42 \mathrm{~b}$, and their associated release for applications including food, pharmaceuticals and packaging.

47 Growth from solutions; A1. Diffusion. 


\section{Introduction}

49 Cyclodextrins (CDs) are naturally synthesized from starch using glycosyltransferase enzymes.

50 These cyclic structures exist in various forms including alpha $(\alpha)$, beta $(\beta)$, gamma $(\gamma)$ and delta

51 ( $\delta)$ form [1]. The difference among these forms is attributed to the numbers of 1,4-linked

52 glucopyranose units which are attached in a cyclic arrangement. The $\alpha, \beta, \gamma$, and $\delta$ forms have 6 ,

537,8 , and 9 glucopyranose units; respectively. As a result, the molecular weight of CDs varies

54 from 972 to 1459 g.mol ${ }^{-1}$ while their cavity diameter ranges between 0.47 and $0.83 \mathrm{~nm}$;

55 respectively [2]. One of the most remarkable properties of CDs is their ability to form inclusion

56 complexes (ICs) with volatile organic compounds due to their hydrophilic exterior and

57 hydrophobic interior. In such complexes, the volatile compounds are entrapped inside the

58 hydrophobic CD pores due to secondary interactions. Such ICs have been widely explored

59 because of their potential applications in pharmaceutical [3], chemical [4], food and packaging

60 industries [5-7].

61 Several researchers have studied CD based ICs. The ability of CDs to host a guest

62 molecule depends on various factors such as the size of the guest molecule, the pore size of the

63 CDs, chemical interactions between functional groups of the guest molecule and hydrophobic

64 pore interior. Veiga et al. [8] prepared tolbutamide urea (TBM) $\beta$-CD complexes using kneading,

65 freeze-drying and co-precipitation. The study concluded increased solubility, dissolution and oral

66 bioavailability of TBM due to the ICs. Almenar et al. [9] studied post-harvest fungal decay

67 inhibition efficacy of acetaldehyde released from $\alpha, \beta$ or $\gamma$-CD acetaldehyde ICs. Effective fungal

68 decay was observed when $\beta$-CD acetaldehyde IC was employed during the marketable period. In

69 another study, Almenar et al. [10] also prepared hexanal and $\beta$-CD ICs in distilled water with

70 different concentrations. The authors encapsulated a maximum of $1.40 \mathrm{ppb}$ hexanal in $\beta$-CD, and 
71 reported that the released hexanal was effective against the growth of fungi. Although $\beta-C D$

72 allows the encapsulation of organic compounds through ICs, the total amount that can be

73 absorbed and later released is still relatively low.

74 Metal-organic frameworks (MOFs) are a new class of microporous coordination polymers,

75 which consists of metal ions and organic linkers [11]. MOFs are well known for their high

76 surface area, gas sorption, gas separation, selectivity and chemical sensing [12-15]. The

77 structural properties of MOFs are unique among other materials including organic, inorganic and

78 hybrid porous structures such as zeolite and activated carbon. These distinctive properties can be

79 accredited to the high porosity of MOFs and their reticulate symmetrical structures, which allow

80 them to host guest molecules like $\mathrm{H}_{2}, \mathrm{CO}_{2}, \mathrm{~N}_{2}$ and $\mathrm{CH}_{4}$ [16-18].

81 Recently, cyclic macromolecules such as CDs [19-22], crown ethers [23], pillararenes [24]

82 and cucurbiturlis [25] with inherently large cavities have been utilized as organic struts for

83 synthesizing MOFs. Such structures offer two porosity levels, the first one exists naturally in

84 these cyclic macromolecules, and the second is created as the result of the chemical coordination

85 between these struts and the metal ions. Gamma CD, a cyclic macromolecule, has been recently

86 coordinated with earth metal ions (e.g., $\mathrm{K}^{+}, \mathrm{Rb}^{+}, \mathrm{Na}^{+}$, and $\mathrm{Cs}^{+}$) to obtain cyclodextrin based

87 metal organic frameworks (CDMOFs) [19]. Gassensmith et al. [20] utilized $\gamma$-CD and $\mathrm{Rb}^{+}$ions

88 based MOF structure, also known as CDMOF-2, for sensing and quantification of $\mathrm{CO}_{2}$ using

89 electrochemical impedance spectroscopy. They credited reversible chemisorption of $\mathrm{CO}_{2}$ to

90 electrochemical sensing of CDMOF-2. Yoon et al. fabricated [21] metal/MOF/metal hetero-

91 structures based memristors using single crystals of CDMOF-2 for storage of electrical

92 information. The ability of these hetero-structures to work as resistive random-access memory

93 (RRAM) was ascribed to the porous structure of MOFs, which allows transportation of ions 
94 when infused with electrolytes. The release of drug encapsulation in the $\gamma$-CD and $\mathrm{K}^{+}$ion MOF

95 structure, generally known as CDMOF-1, has been studied for drug carrier applications using

96 Monte Carlo simulations [22]. In their study, researchers observed strong interactions between

97 the metal centers of the MOF and the carbonyl group present in analgesic drug, ibuprofen [22].

98 In this study, we synthesized two different $\gamma-\mathrm{CD}-\mathrm{K}^{+}$ions based MOFs using potassium

99 hydroxide and potassium benzoate as sources of $\mathrm{K}^{+}$ion, referred hereafter as CDMOF-a and

100 CDMOF-b; respectively. Gamma-CDs were chosen as linkers due to their bio-based nature as

101 well as their unique ability to form ICs. These CDMOFs were synthesized because of the non-

102 toxic nature of alkali metals, presence of polar groups, open metal sites and the ability of various

103 CDs to form ICs [26-28]. The main objectives of this study were: $a$ ) to synthesize CDMOF-a and

104 CDMOF-b; $b$ ) to determine the physical and thermal characteristics of CDMOF-a and CDMOF-

$105 \mathrm{~b}$ crystals; and $c$ ) to run a proof-of-concept of the ability to encapsulate and release a selected

106 organic compound, acetaldehyde, which is known for its anti-fungal activity [9]. To the best of

107 the authors' knowledge, no study has focused on encapsulation and release kinetics of 108 acetaldehyde in CDMOFs.

109 2. Methodology

$110 \quad 2.1$ Materials

111 Gamma CD (purity > 99\%, food grade) was donated by Wacker Chemical Corporation (Adrian,

112 MI, USA). Potassium hydroxide (KOH) pellets (ACS reagent, purity $\geq 85 \%$ ), and potassium

113 benzoate $\left(\mathrm{C}_{7} \mathrm{H}_{5} \mathrm{KO}_{2}\right)$ were purchased from Columbus Chemical Industries, Inc. (Phoenix, AZ,

114 USA). Anhydrous methanol (purity > 99.8\%) and acetaldehyde (purity $\geq 99 \%$, FCC) were

115 purchased from Sigma-Aldrich Corp. (Saint Louis, MO, USA). Distilled and deionized water 
116 was purchased from Avantor Performance Materials (Center Valley, PA, USA). All materials

117 were used as received unless otherwise indicated.

\section{$118 \quad 2.2$ Synthesis and Activation of CDMOF}

119 The CDMOFs were synthesized as per Smaldone et al. [26]. One mmol (1.30 g) of $\gamma$ 120 cyclodextrin and $8 \mathrm{mmol}(0.45 \mathrm{~g})$ of $\mathrm{KOH}$ were dissolved in $20 \mathrm{~mL}$ of deionized water and

121 labeled in this work as CDMOF-a. On the other hand, $1.6 \mathrm{mmol}(0.256 \mathrm{~g})$ of $\mathrm{C}_{7} \mathrm{H}_{5} \mathrm{KO}_{2}$ and 0.2 $122 \mathrm{mmol}(0.26 \mathrm{~g})$ of $\gamma$-CD were diluted in $5 \mathrm{~mL}$ of deionized water to synthesize CDMOF-b. The 123 solutions were stirred continuously for $6 \mathrm{~h}$ at $500 \mathrm{rpm}$ followed by slow vapor diffusion of 124 methanol over a period of 3 to $7 \mathrm{~d}$. After the CDMOF crystals were produced in the solution with 125 an average yield of $1.25 \mathrm{~g}$ for the $\mathrm{CD}$ and $\mathrm{KOH}$, and $0.30 \mathrm{~g}$ for the $\mathrm{CD}$ and $\mathrm{C}_{7} \mathrm{H}_{5} \mathrm{KO}_{2}$, the 126 crystals were washed with methanol to remove unreacted potassium ions and then filtered 127 (samples were labeled as as-synthesized). After synthesis, the CDMOFs were activated in a 128 vacuum oven at $23^{\circ} \mathrm{C}$ for $10 \mathrm{~h}$ at $4 \mathrm{kPa}(30 \mathrm{mmHg})$. Then, the temperature was increased to $45^{\circ} \mathrm{C}$ 129 and maintained for an additional $12 \mathrm{~h}$ under the same vacuum pressure $4 \mathrm{kPa}$ (samples were $130 \quad$ labeled as activated).

\section{$131 \quad 2.3$ Surface Area and Pore Size}

132 The gas sorption experiments were conducted using an iQMicropore-XR (Quantachrome 133 Instruments, Boynton Beach, FL, USA). The surface area, pore sizes and diameters of the 134 CDMOFs were calculated using the Brunauer-Emmett-Teller (BET) and Langmuir methods. 135 Samples between 0.1 and $0.3 \mathrm{~g}$ of each synthesized CDMOF-a and CDMOF-b crystals were 136 dehydrated for $10 \mathrm{~h}$ of vacuum pressure at $0.133 \mathrm{kPa}\left(1\right.$ Torr) at $25 \pm 0.1{ }^{\circ} \mathrm{C}$ followed by heating 137 at $45{ }^{\circ} \mathrm{C}$ for $12 \mathrm{~h}$ under the same pressure. The specimens were then transferred to the sorption 
138 station where the $\mathrm{N}_{2}$ adsorption took place at $77.3 \mathrm{~K}$ and $\mathrm{N}_{2}$ gas sorption at a relative pressure

139 varying from $10^{-5}$ to 0.99 [29].

$140 \quad 2.4$ Thermogravimetric Analysis (TGA)

141 Thermal stability of CDMOF-a and CDMOF-b crystals were evaluated using a TGA model

142 2950, from TA Instruments (New Castle, DE, USA). A sample weight of $5 \mathrm{mg}$ of activated

143 CDMOF-a and CDMOF-b were utilized to perform the studies. Samples were heated from 25 to

$144450{ }^{\circ} \mathrm{C}$ at a rate of $10{ }^{\circ} \mathrm{C} \cdot \mathrm{min}^{-1}$. Data were collected and analyzed using the Universal Analysis

145 software version 2000 from TA Instruments.

$1462.5 X$-Ray Diffraction (XRD)

147 The CDMOF-a and CDMOF-b activated crystals were examined using a Bruker D8 advance X-

148 ray diffractometer (Bruker $\mathrm{AXS} \mathrm{GmbH}$, Karlsruhe, Germany) using $\mathrm{Cu} \mathrm{K} \alpha(\lambda=0.154 \mathrm{~nm})$

149 radiations at $40 \mathrm{kV}, 40 \mathrm{~mA}$. The samples were studied using $1.2 \mathrm{~mm}$ primary beam slit, and 2.0

$150 \mathrm{~mm}$ detector slit over 3 to $40^{\circ} 2$ theta angles with increments at $0.02^{\circ}$ per min.

$151 \quad 2.6$ Scanning Electron Microscopy (SEM)

152 To study the topography activated CDMOF-a and CDMOF-b crystals were sputter coated with

153 approx. $8 \mathrm{~nm}$ thick platinum coating. The coated specimens were examined using a JEOL JSM

154 6410LV (JEOL Ltd., Tokyo, Japan) SEM, equipped with a tungsten filament, at 10kV 155 accelerating voltage.

$156 \quad 2.7$ Encapsulation and Release Method

157 Acetaldehyde encapsulation was carried out after activating the CDMOF-a and CDMOF-b. First,

$1581 \mathrm{~g}$ of activated CDMOF-a or CDMOF-b was placed in a small aluminum pan that was placed in

159 a $2 \mathrm{~L}$ glass jar. Acetaldehyde $(1 \mathrm{~mL})$, previously stored in a conventional refrigerator at $5{ }^{\circ} \mathrm{C}$, 
161 Temperature Cabinet at $25 \pm 0.1{ }^{\circ} \mathrm{C}$ with a controller device from Sable System International,

162 NA, USA. The glass jar was sealed with a metal screw cap for $24 \mathrm{~h}$ in the chamber to insure the

163 acetaldehyde penetration in the CDMOFs voids (samples were labeled as encapsulated).

164 The release amount of acetaldehyde from the encapsulated CDMOFs was determined by 165 transferring the encapsulated CDMOFs to a new $2 \mathrm{~L}$ glass jar. The acetaldehyde concentration in

166 the headspace was measured at $25 \pm 0.1^{\circ} \mathrm{C}$. A gas chromatographer (GC), from Hewlett Packard 167 GC 6890, CA, USA, with a flame ionization detector (FID) and a HP-5 column dimension $30 \mathrm{~m}$ $168 \times 0.32 \mathrm{~mm} \times 0.25 \mu \mathrm{m}$, was used to determine the headspace concentration of acetaldehyde 169 release in the jar. An airtight gas micro-syringe was used to extract $25 \mu \mathrm{L}$ from the jar headspace 170 through a rubber septum placed in the metal screw lid and injected into the GC. Samples $(25 \mu \mathrm{L})$

171 from the headspace were injected to the $\mathrm{GC}$ at $1,2,3,4,5,6$, and $24 \mathrm{~h}$ after the encapsulated 172 CDMOFs were introduced in the $2 \mathrm{~L}$ jar. The GC setting conditions were as follows; oven 173 temperature initially $80{ }^{\circ} \mathrm{C}$ for $2 \mathrm{~min}$, and increased to $200{ }^{\circ} \mathrm{C}$ at $10{ }^{\circ} \mathrm{C} \cdot \mathrm{min}^{-1}$. The detector and 174 the inlet temperatures were at $240{ }^{\circ} \mathrm{C}$. A calibration curve between 50 to $500 u \mathrm{~L} / \mathrm{L}$ of 175 acetaldehyde concentration was constructed at $25 \pm 0.1{ }^{\circ} \mathrm{C}$ with an adjusted R-square $=0.990$. 176 Samples were tested in triplicate.

\section{$177 \quad 2.8$ Color Measurements}

178 Encapsulated CDMOF-a and CDMOF-b specimens were examined using a Mold U-4100 179 HunterLab LabScan XE (Reston, VA, USA) colorimeter for color changes after $24 \mathrm{~h}$ of 180 activation and after encapsulation. $L^{*}$ Lightness, $a^{*}$ from red positive to green negative, $b^{*}$ from 181 yellow positive to blue negative were obtained. $\Delta E$ total color change was calculated using the 182 equation $\Delta E=\left[\left(\Delta L^{*}\right)^{2}+\left(\Delta a^{*}\right)^{2}+(\Delta b *)^{2}\right]^{1 / 2}$. 
184 The entire data were analyzed using Tukey's HSD (Honestly Significant Differences) for the 185 means comparisons with $\alpha=0.05$ at $95 \%$ confidence interval using SAS 9.4 Software (SAS 186 Institute Inc., Cary, NC, USA).

\section{Results and Discussion}

\subsection{Synthesis and Activation of CDMOF}

189 CDMOF-a and CDMOF-b were successfully produced with $\mathrm{KOH}$ and $\mathrm{C}_{7} \mathrm{H}_{5} \mathrm{KO}_{2}$ respectively by 190 using vapor diffusion crystallization process at room temperature $\left(23{ }^{\circ} \mathrm{C}\right)$. Methanol, a popular

191 solvent for crystal growth, was used because its high vapor pressure and reasonably good 192 solubility aids the crystal growth. CDMOF-b crystals synthesized in 2-3 d whereas CDMOF-a 193 crystal took approximately $1.3 \mathrm{~d}$ to crystallize from the solution, indicating the slow nucleation 194 rate in $\gamma$-CD- $\mathrm{C}_{7} \mathrm{H}_{5} \mathrm{KO}_{2}$ solution and CDMOF-b crystal growth as compared to CDMOF-a, which 195 may be affected by various factors such as the basicity of the solution, source of the metal ions, 196 synthesis methodology and reactants concentration [30, 31]. Biemmi et al. [30] examined three 197 different sources of $\mathrm{Zn}$ : (i) Zinc (II) Nitrate $\left(\mathrm{Zn}\left(\mathrm{NO}_{3}\right)_{2} \cdot 6 \mathrm{H}_{2} \mathrm{O}\right)$, (ii) Zinc acetate $198\left(\mathrm{Zn}\left(\mathrm{CH}_{3} \mathrm{COO}\right)_{2} \cdot 2 \mathrm{H}_{2} \mathrm{O}\right)$, and (iii) Zinc Oxide $(\mathrm{ZnO})$, for the synthesis of MOF-5. Although, MOF-5 199 synthesized using all the three $\mathrm{Zn}$ sources mentioned above, the metal source significantly 200 impacted both the morphology and crystal size. Smaller crystals were reported for Zinc acetate, 201 the authors credited it to the faster nucleation due to higher basicity as compared to Zinc nitrate. 202 Michida et al. [28] monitored the $\mathrm{pH}$ of the solution during the CDMOF synthesis, and reported 203 higher yield when the crystals are grown from solution with higher basicity. We obtained $70 \%$ 204 yield for the synthesis of CDMOF-a crystals and 50\% yield for CDMOF-b crystals. The higher 205 yield in case of CDMOF-a may be correlated to higher basicity in the CDMOF-a solution. 
207 Porous materials are meticulously tailored to achieve specific objectives. Physical characteristics

208 such as surface area, pore size and pore volume have significant impact on the functionality, 209 selectivity and intrinsic surface energy of these molecules. The three-dimensional coordination 210 arrangement between organic linkers and ions significantly influences the theoretical pore 211 volume and the surface area. The $\mathrm{N}_{2}$ isotherms of CDMOF-a and CDMOF-b samples are 212 represented in Figure 1. Type-1 isotherms, also known as Langmuir isotherm, were observed for 213 both the CDMOFs, as per International Union of Pure and Applied Chemistry (IUPAC) 214 classification. The surface area, pore size and pore volume of CDMOF-a and CDMOF-b is 215 summarized in Table 1. High adsorption at low partial pressure indicates microporous nature of 216 the material and correlates with high surface energy. As observed from Table 1, CDMOF-a has 217 more than two times the surface area of CDMOF-b. This variation between the measured surface 218 areas may be attributed to the difference in the crystal structure of the two MOFs and presence of 219 the benzoate counter-anions in the pores of CDMOF-b. CDMOF-a, $\mathrm{K}_{2}\left(\mathrm{C}_{48} \mathrm{H}_{80} \mathrm{O}_{40}\right)(\mathrm{OH})_{2}$, has 220 body centered cubic crystal structure whereas CDMOF-b, $\mathrm{K}_{4}\left(\mathrm{C}_{96} \mathrm{H}_{160} \mathrm{O}_{80}\right)\left(\mathrm{C}_{7} \mathrm{H}_{5} \mathrm{O}_{2}\right)_{2}-(\mathrm{OH})_{2}$ has 221 trigonal crystal structure $[26,32]$.

222 The theoretical pore density of CDMOF-a has been calculated as $0.56 \mathrm{~g} \cdot \mathrm{cm}^{-3}$. [26], 223 which is close to the measured density $\sim 0.50 \mathrm{~g} \cdot \mathrm{cm}^{-3}$. On another note, the micro-pore volume 224 for CDMOF-b was measured at $\sim 0.18 \mathrm{~cm}^{3} \cdot \mathrm{g}^{-1}$, which can be attributed to the crystal structure 225 and the fact that the pores are partly occupied by the benzoate counter-anions [26, 32]. This is 226 also in line with Forgan et al. [32] who reported the presence of stabilized benzoate counter227 anions in the $\gamma$-CD dimers due to formation of two hydrogen bonds between $\gamma$-CD and benzoate 
228 anions. Figure 2a shows the location of benzoate counter-anions in the CDMOF-b structure, and

229 Figure $2 \mathrm{~b}$ represents the interactions between CD moiety and benzoate anion.

\subsection{Thermogravimetric Analysis (TGA)}

232 The thermograms of CDMOF-a and CDMOF-b are represented in Figure 3. The 233 thermogravimetric studies indicate $\sim 8 \%$ weight loss in CDMOF-a and CDMOF-b upto $150^{\circ} \mathrm{C}$.

234 This weight loss can primarily be associated with the loss of water molecules residing in the

235 pores of these MOF structures. CDMOF-b is thermally more stable as compared to CDMOF-a.

236 The sharp weight loss in CDMOF-a around $264{ }^{\circ} \mathrm{C}$ can be ascribed to the destruction of

237 hydroxyl groups present in the $\gamma$-CD. On the other hand, in the case of CDMOF-b the first 238 degradation peak was observed at approximately $315^{\circ} \mathrm{C}$. Further weight loss peaked around $239428^{\circ} \mathrm{C}$ due to the decomposition of glucopyranose units, as observed by their dervative profiles 240 (DTGA). Relatively higher thermal stability of the hydroxyl groups in CDMOF-b can be 241 ascribed to the secondary interaction with the benzoate counter-anions present in the structure.

\subsection{X-Ray Diffraction (XRD)}

244 Diffraction patterns of CDMOF-a, $\mathrm{K}_{2}\left(\mathrm{C}_{48} \mathrm{H}_{80} \mathrm{O}_{40}\right)(\mathrm{OH})_{2}$, CDMOF-b are represented in Figures 4a 245 and 4b; respectively, matching previously reported XRD patterns [26]. The details of these 246 crystals have been previously reported [26, 32] and freely accessible in the database of The 247 Cambridge Crystallographic Data Centre under the CCDC numbers 773709 and 773711. $248 \mathrm{~K}_{2}\left(\mathrm{C}_{48} \mathrm{H}_{80} \mathrm{O}_{40}\right)(\mathrm{OH})_{2}$, crystals have body centered cubic crystal, and they represent space group 249 I432 with axial lengths $\mathrm{a}=\mathrm{b}=\mathrm{c}=31.006 \AA$ and inter-axial angles $\alpha=\beta=\gamma=90^{\circ}$. The 250 formation of cubic crystal structure has been ascribed to the eight-fold symmetry offered by $\gamma$ - 
$251 \mathrm{CD}$ [29]. On the other hand, CDMOF-b, $\mathrm{K}_{4}\left(\mathrm{C}_{96} \mathrm{H}_{160} \mathrm{O}_{80}\right)\left(\mathrm{C}_{7} \mathrm{H}_{5} \mathrm{O}_{2}\right)_{2}(\mathrm{OH})_{2}$, has trigonal crystal 252 system representing space group R32 with axial lengths $\mathrm{a}=\mathrm{b}=42.6517 \AA ⿻ \mathrm{c}=28.4636 \AA$ and 253 inter-axial angles $\alpha=\beta=90^{\circ}, \gamma=120^{\circ}$.

\subsection{Scanning Electron Microscopy (SEM)}

256 External shape and size of the crystal are important for employing these crystals for various 257 industrial applications [31]. In addition, size variations can alter the physical properties of the 258 MOF particles. Morphology, size, shape and visible appearance of a crystal are influenced by 259 source of metal ion, solvent, impurities, nucleation, crystal growth pattern and MOF crystal 260 synthesis parameters such as temperature and pressure. [31-34]. SEM images of CDMOF-a and 261 CDMOF-b are represented in Figure 5a, 5b and 5c, 5d; respectively. CDMOF-b has twice the

262 size of CDMOF-a. The larger size of CDMOF-b can be ascribed to lower nucleation rate and 263 slower crystal growth [30,34], which may have been influenced by the presence of benzoate 264 counter-anions in the solution.

\subsection{Encapsulation and release of acetaldehyde}

267 Acetaldehyde, a naturally occurring antifungal, is a chemically reactive compound. It is water268 soluble and volatile in nature, which poses retention and stability challenges. Cyclodextrin 269 inclusion complexes have been utilized for retention and delivery of controlled release of 270 acetaldehyde [9]. Two level of pores exist in the CDMOF which can potentially host

271 acetaldehyde a. pore (cavity), which exist naturally in the cyclic CD molecules with diameter 272 ranging from 7.5-8.3 $\AA$ and $\mathbf{b}$. pores in the MOF structure due to coordination of the CDs with 
273 the $\mathrm{K}^{+}$ions as well as pore of porous MOF structure. Both CDMOF-a and CDMOF-b were

274 evaluated as a proof of concept for the encapsulation of acetaldehyde. We successfully

275 encapsulated acetaldehyde in CDMOF-b as supported by the release kinetics and TGA studies.

276 The successful encapsulation of acetaldehyde in the $\gamma$-CDMOF-b can be ascribed to the strong

277 quadrupole-quadrupole interactions between acetaldehyde and electron rich aromatic ring

278 present in the benzoate counter-anion present in the MOF structure [31, 35].

Wu et al. [35] studied adsorption mechanism of acetaldehyde on MOF-5 using density

280 functional theory. They observed strong secondary interactions between aromatic rings present in

281 the organic linkers and carbonyl group present in the acetaldehyde with adsorption energy -10

$282 \mathrm{~kJ} / \mathrm{mol}$. They also observed that any electron withdrawing groups attached to benzene ring

283 increases the acetaldehyde adsorption capacity of MOF-5.

The release of acetaldehyde from encapsulated CDMOF-b with time can be observed in

285 Figure 6. The acetaldehyde release from $1 \mathrm{~g}$ of CDMOF-b steadily increased and peaked to 53

$286 \mu \mathrm{g} /$ after $5 \mathrm{~h}$, the release quantity dropped further with time. After $24 \mathrm{~h}$, the concentration of

287 acetaldehyde in the headspace dropped to around $30 \mu \mathrm{g}$ acetaldehyde per $1 \mathrm{~g}$ of CDMOF.

288 Almenar et al. [9] observed similar trends in the acetaldehyde release kinetics study from $\beta$-CD

289 acetaldehyde ICs. However, the peak quantity of acetaldehyde released from CDMOF-b is two

290 order of magnitude higher than the release reported in the $\beta$-CD ICs. It can be ascribed to high

291 acetaldehyde sorption capacity of CDMOF-b as compared to $\beta$-CD due to its high specific

292 surface area and microporous structure of CDMOF-b. We could not find any study focused on

293 encapsulation and release of acetaldehyde in $\gamma$-CD. Figure 6 also shows a large release variation

294 of acetaldehyde at higher rates, which could be attributed to preferential desorption of

295 acetaldehyde and/or variation on efficiencies on the encapsulation method. Further assessment is 
296 required to streamline the release of acetaldehyde from CDMOF-b. However, this information

297 provides encouraging results of a system that could create ICs with larger amount of the organic 298 compounds.

To quantify the amount of acetaldehyde encapsulated in the CDMOF-b, we utilized TGA

300 studies. Figure 7 shows TGA thermographs of as-synthesized, activated and encapsulated

301 CDMOF-b. All the samples demonstrated good thermal stability below $250^{\circ} \mathrm{C}$. As synthesized

302 samples lost $\sim 12-14 \%$ weight at $100^{\circ} \mathrm{C}$ as compared to its actual weight which can be ascribed

303 to loss of water present in the CDMOF-b pores. Activated samples lost around $4 \%$ weight, this

304 weight could be associated with adsorption of moisture or other molecules during the handling of

305 CDMOF-b before TGA studies. Encapsulated samples lost $\sim 13.75 \%$ wt. at $\sim 150^{\circ} \mathrm{C}$, which

306 could primarily be associated with the loss of the acetaldehyde present in the CDMOF-b pores.

307 The thermal degradation onset temperatures for as synthesized, activated and encapsulated $\gamma$ -

308 CDMOF-b were observed between $250-300^{\circ} \mathrm{C}$.

Although CDMOF-a has higher surface area than CDMOF-b, we struggled to encapsulate

310 the acetaldehyde in CDMOF-a due to aldol self-condensation reaction, represented in Figure 8,

311 because of the presence of hydroxide counterions in the pore of MOF which may have released

312 from the potassium hydroxide during the MOF synthesis. Aldol condensation was also evident as

313 color change in the CDMOF-a crystals from white to brownish red in couple of minutes during

314 the encapsulation trials due to formation of resinous material. Researchers [36] have reported

315 that aldehydes can undergo self-condensation reaction producing reddish-brown colored resinous

316 material. In the case of CDMOF-b no chemical reaction has occurred. However, carboxylate

317 moieties present in the benzoate anions bonded with hydroxyl groups present in the CDMOF-b

318 due to hydrogen bonding as shown in Figure 2. 
321 Encapsulated CDMOF-a and CDMOF-b and activated CDMOF-a and CDMOF-b crystals were 322 examined using the colorimeter to capture and record the color changes due to aldol 323 condensation reaction that occurred during encapsulation of acetaldehyde in CDMOF-a. Color 324 parameters of CDMOF-a and CDMOF-b exposed to acetaldehyde are represented in Table 2. 325 The distinguishing color change was recorded in the encapsulated CDMOF-a, where the value of $326 b^{*}$ yellowness and redness were very high compared to the negative values of the encapsulated 327 CDMOF-b toward the blue and green regions, respectively. In general, the brightness values of 328 the crystal decreased in the encapsulated samples, which is an indication of the luminosity 329 decreasing. The redness and yellowness in the reacted CDMOF-a again supports the formation of 330 reddish-brown colored resinous material due to the aldol condensation reaction of acetaldehyde.

331 Color changes and acetaldehyde release from CDMOF-b did not support any chemical reaction, 332 throughout the inclusion time and release. Thus, CDMOF-b may be suitable to build inclusion 333 complexes for various organic compounds.

\section{4. Conclusions}

336 In this study, two different types of stable, accessible, high surface area and microporous sugar 337 moiety based MOF structures with high density of reactive and accessible hydroxyl groups were 338 synthesized. These MOF structures, CDMOF-a and CDMOF-b, were evaluated for the 339 encapsulation of acetaldehyde and its release kinetics using GC and TGA. It was observed that 340 CDMOF-b can successfully host and release acetaldehyde molecules into its pores. However, 
341 aldol condensation reaction was observed during encapsulation of acetaldehyde in CDMOF-a

342 molecules, which induced color changes in CDMOF-a crystals from colorless to red color

343 powder due to the formation of resinous material.

\section{ACKNOWLEDGEMENTS}

345 The authors would like to thank Omar Dib for his insight and help during this work, Aaron

346 Walworth, Michigan State University, for his help in the SoP Laboratory. Edgar Castro Aguirre

347 for his assistance with diffraction studies, and Hayati Samsudin for helping with the comments

348 and suggestions for this work. RA thanks partial support of the USDA National Institute of Food

349 and Agriculture and Michigan AgBioResearch, Hatch project R. Auras. 


\section{References}

352 1. J. Szejtli, Chem. Rev., 1998, 98.5, 1743-1754.

353 2. E. M. Del Valle, Process Biochem., 39 (2004) 1033-1046.

354 3. Q. D. Hu, G. P. Tang, P.K. Chu, Acc. Chem. Res., 47 (2014), 2017-2025.

4. B. S. Muñoz, M. A. Martìn, B . del Castillo, J. C. Menéndez, L. Vázquez, D. A. Lerner, J. Pharm. Biomed. Anal., 14 (1996) 909-915.

5. E. Almenar, R. Auras, Harte, B.; Rubino M. US Patent No. US20070207981 A1., 2007.

6. M. J. Joo, C. Merkel, R. Auras, E. Almenar, Int. J. Food Microbiol., 153 (2012) 297-305.

7. M. Singh, R. Sharma, U. Banerjee, Biotechnol. Adv., 20 (2002), 341-359.

8. F. Veiga, J. Teixeira-Dias, F. Kedzierewicz, A. Sousa, P. Maincent, Int. J. Pharm., 129 (1996), 63-71.

9. E. Almenar, R. Auras, P. Wharton, M. Rubino, B. Harte, J. Agric. Food Chem., 55 (2007) 7205-7212.

10. E. Almenar, R. Auras, M. Rubino, B. Harte, Int. J. Food Microbiol., 118 (2007) 164-172.

11. S. L. James, Chem. Soc. Rev., 32 (2003) 276-288.

12. H. K. Chae, D.Y. Siberio-Pérez, J. Kim, Y. Go, M. Eddaoudi, A. J. Matzger, M. O'Keeffe, O. M. Yaghi, Nature 427 (2004) 523-527.

13. S. S. Y. Chui, S. M. F. Lo, J. P. Charmant, A. G. Orpen, I. D. Williams, Science, 283 (1999) 1148-1150.

14. H. Li., M. Eddaoudi, T. L. Groy, O. Yaghi, J. Am. Chem. Soc., 120 (1998) 8571-8572.

15. H. Li., M. Eddaoudi, M. O'Keeffe, O. M. Yaghi, Nature, 402 (6759) (1999), 276-279.

16. K. Chue, J. Kim, Y. Yoo, S. Cho, R. Yang, Ind. Eng. Chem. Res., 34 (1995), 591-598.

17. J. Moellmer, A. Moeller, F. Dreisbach, R. Glaeser, R. Staudt, Microporous Mesoporous Mater., 138 (2011) 140-148.

18. N. L. Rosi, M. Eddaoudi, J. Kim, M. O'Keeffe, O. M. Yaghi, CrystEngComm, 4 (2002) 401404.

19. J. F. Stoddart, R. S. Forgan, R. A. Smaldone, J. J. Gassensmith, US Patent No. 2012007904 A1, 2011. 
20. J. J. Gassensmith, H. Furukawa, R. A. Smaldone, R. S. Forgan, Y. Y. Botros, O. M. Yaghi, J. F. Stoddart, J. Am. Chem. Soc., 133 (2011), 15312-15315.

21. S. M. Yoon, S. C. Warren, B. A. Grzybowski, Angew. Chem. Int. Ed., 53 (2014) 4437-4441.

22. M. C. Bernini, D. Fairen-Jimenez, M. Pasinetti, A. J. Ramirez-Pastor, R Q. Snurr, J. Mater. Chem. B, 2 (2014) 766-774.

23. C. J. Pedersen, J. Am. Chem. Soc., 89 (1967) 7017-36.

24. T. Ogoshi, S. Kanai, S. Fujinami, T. Yamagishi, Y. Nakamoto, J. Am. Chem. Soc., 130 (2008) 5022-23.

25. K. Kim, Chem. Soc. Rev., 31 (2002) 96-107.

26. R. A. Smaldone, R. S. Forgan, H. Furukawa, J. J. Gassensmith, A. M. Slawin, O. M. Yaghi, J. F. Stoddart, Angew. Chem. Int. Ed., 49 (2010) 8630-8634.

27. J. J. Gassensmith, J. Y. Kim, J. M. Holcroft, O. K. Farha, J. F. Stoddart, J. T. Hupp, N. C. Jeong, J. Am. Chem. Soc., 136 (2014) 8277-8282.

28. W. Michida, M. Ezaki, M. Sakuragi, G. Guoqing, K. Kusakabe, Cryst. Res. Technol., 50 (2015) 556-559.

29. S. Lowell, J. E. Shields, M. A. Thomas, M. Thommes, In Characterization of Porous Solids and Powders: Surface Area, Pore Size and Density. Springer (origanally by Kluwer Academic Publishers): New York, 2004.

30. E. Biemmi, S. Christian, N. Stock, T. Bein, Microporous Mesoporous Mater., 117 (2009) $111-117$.

31. N. Stock, S. Biswas, Chem. Rev., 112 (2012) 933-969.

32. R. S. Forgan, R. A. Smaldone, J. J. Gassensmith, H. Furukawa, D. B. Cordes, Q. Li, C. E. Wilmer, Y. Y. Botros, R. Q. Snurr, A. M. Z. Slawin, J. F. Stoddart, J. Am. Chem. Soc., 134 (2012) 406-417.

33. P. Falcaro, A. J. Hill, K. M. Nairn, J. Jasieniak, J. I. Mardel, T. J. Bastow, S. C. Mayo, M. Gimona, D. Gomez, H. J. Whitfield, R. Ricco, A. Patelli, B. Marmiroli, H. Amenitsch, T. Colson, L. Villanova, D. Buso, Nat. Commun., 2010, 2, 237.

34. M. K. Smith, S. R. Angle, B. H. Northrop, J. Chem. Educ., 2015, 92, 368-372.

35. Y. Wu, D. Liu, Y. Wu, H. Xi, Chemical Industry and Engineering Society of China (CIESC Journal) 64 (2013) 2891-2897.

36. Ballard SA, Haury VE. Hydrogenated Ketone Resins. US Patent No. 2380142, 1945. 


\section{List of Tables}

414 Table 1. Surface area, pore size and pore volume of $\gamma$-CDMOF-a and $\gamma$-CDMOF-b

415 Table 2. Color measurements of CDMOFs before and after exposure to acetaldehyde

\section{$417 \quad$ List of Figures}

418 Figure 1. $\mathrm{N}_{2}$ sorption/desorption isotherms of $\gamma$-CDMOF-a and $\gamma$-CDMOF-b

419 Figure 2. a. Location of benzoate anion in the CD MOF and b. interactions between CD moiety 420 and benzoate anion

421 Figure 3. Thermo-gravimetric analysis of $\gamma$-CDMOF-a and $\gamma$-CDMOF-b

422 Figure 4. X-Ray diffraction of activated $\gamma$-CDMOF-a and $\gamma$-CDMOF-b

423 Figure 5. a). SEM image-I of CDMOF-a scale size $50 \mu \mathrm{m}$ b). SEM image-II of CDMOF-a scale 424 size $50 \mu \mathrm{m} \mathrm{c}$ ). SEM image-I of CDMOF-b scale size $100 \mu \mathrm{m}$. d). SEM image-II of CDMOF-b 425 scale size $200 \mu \mathrm{m}$.

426 Figure 6. Release kinetics of acetaldehyde per gram of $\gamma$-CDMOF-b

427 Figure 7. Thermo-gravimetric analysis of as-synthesized, activated, and encapsulated $\gamma$ 428 CDMOF-b

429 Figure 8. Schematic representation of aldol condensation reaction 
433 Table 1. Surface area (SA), pore size and pore volume of CDMOF-a and CDMOF-b

\begin{tabular}{cccccc}
\hline CDMOFs & $\begin{array}{c}\text { BET SA } \\
\left(\mathbf{m}^{\mathbf{2}} \cdot \mathbf{g}^{\mathbf{- 1}}\right)\end{array}$ & $\begin{array}{c}\text { Langmuir } \\
\left.\mathbf{S A}^{\mathbf{S A}} \mathbf{g}^{-\mathbf{1}}\right)\end{array}$ & $\begin{array}{c}\text { Micropore } \\
\text { volume } \\
\left(\mathbf{c m}^{\mathbf{3}} \cdot \mathbf{g}^{-\mathbf{1}}\right)\end{array}$ & $\begin{array}{c}\text { Total Pore } \\
\text { volume } \\
\left(\mathbf{c m}^{\mathbf{3}} \cdot \mathbf{g}^{-\mathbf{1}}\right)\end{array}$ & $\begin{array}{c}\text { Average Pore } \\
\text { Radius }(\mathbf{n m})\end{array}$ \\
\hline CDMOF-a & $1229 \pm 6^{\mathrm{a}}$ & $1376 \pm 18^{\mathrm{a}}$ & $0.49 \pm 0.02^{\mathrm{a}}$ & $0.50 \pm 0.02^{\mathrm{a}}$ & $0.79 \pm 0.01^{\mathrm{a}}$ \\
\hline CDMOF-b & $417 \pm 110^{\mathrm{b}}$ & $607 \pm 102^{\mathrm{b}}$ & $0.18 \pm 0.03^{\mathrm{b}}$ & $0.22 \pm 0.03^{\mathrm{b}}$ & $0.40 \pm 0.40^{\mathrm{a}}$
\end{tabular}

434 Note: Values in the same column with the same superscript letters are not significantly different 435 at $\alpha=0.05$. Micropore volumes were calculated at a radius of $2 \mathrm{~nm}$, whereas total pore volumes 436 were obtained at the relative pressure $\mathrm{P} / \mathrm{Po}=0.99$.

437

Table 2. Color measurements of CDMOFs before and after exposure to acetaldehyde

\begin{tabular}{lcccc}
\hline & $\boldsymbol{L}^{*}$ & $\boldsymbol{a}^{*}$ & $\boldsymbol{b}^{*}$ & $\boldsymbol{\Delta}$ \\
\hline CDMOF-a & $80.8 \pm 2.1^{\mathrm{a}}$ & $-0.05 \pm 0.1^{\mathrm{a}}$ & $-0.2 \pm 0.1^{\mathrm{a}}$ & $80.8 \pm 2.1^{\mathrm{a}}$ \\
\hline CDMOF-b & $72.4 \pm 2.6^{\mathrm{b}}$ & $-0.5 \pm 0.1^{\mathrm{a}}$ & $-0.3 \pm 0.3^{\mathrm{a}}$ & $72.4 \pm 2.6^{\mathrm{b}}$ \\
\hline CDMOF-a Encapsulated & $46.9 \pm 0.6^{\mathrm{c}}$ & $15.9 \pm 0.4^{\mathrm{b}}$ & $39.4 \pm 0.6^{\mathrm{b}}$ & $63.3 \pm 0.4^{\mathrm{c}}$ \\
\hline CDMOF-b Encapsulated & $48.2 \pm 0.8^{\mathrm{c}}$ & $-1.4 \pm 0.0^{\mathrm{c}}$ & $0.9 \pm 0.2^{\mathrm{c}}$ & $48.2 \pm 0.8^{\mathrm{d}}$
\end{tabular}

Values in the same column with the same superscript letters are not significantly different at $\alpha=$ $440 \quad 0.05$. 


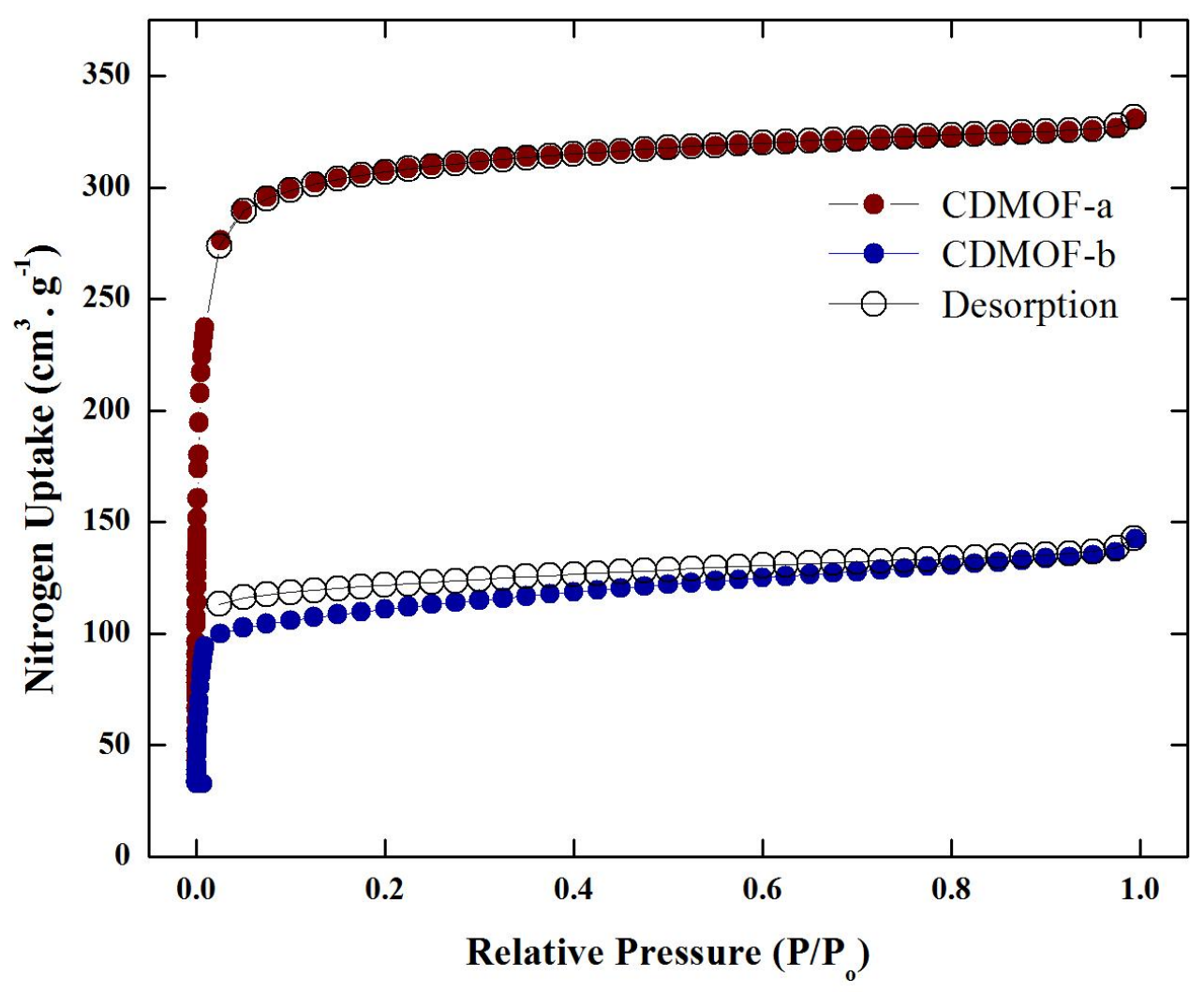

444

Figure 1. $\mathrm{N}_{2}$ sorption/desorption isotherms of CDMOF-a and CDMOF-b 


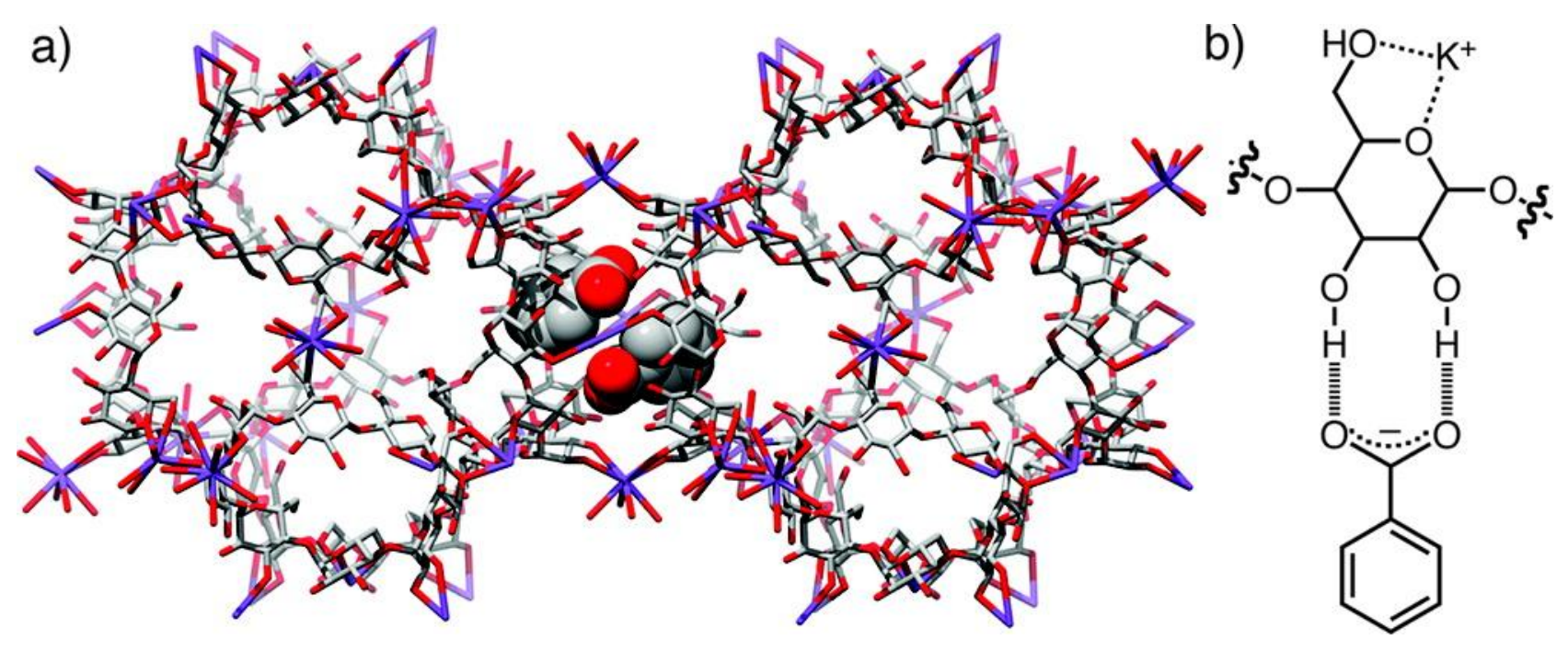

452 Figure 2. a. Location of the benzoate anion in the $\gamma$-CDMOF-b structure as stick representation 453 of the crystal structure of CDMOF - benzoate anions are represented as space-filling mode, and 454 b. interactions between CD moiety and benzoate anion, reprinted with permission from Forgan $e t$ 455 al. [32]. Copyright 2011 American Chemical Society. 


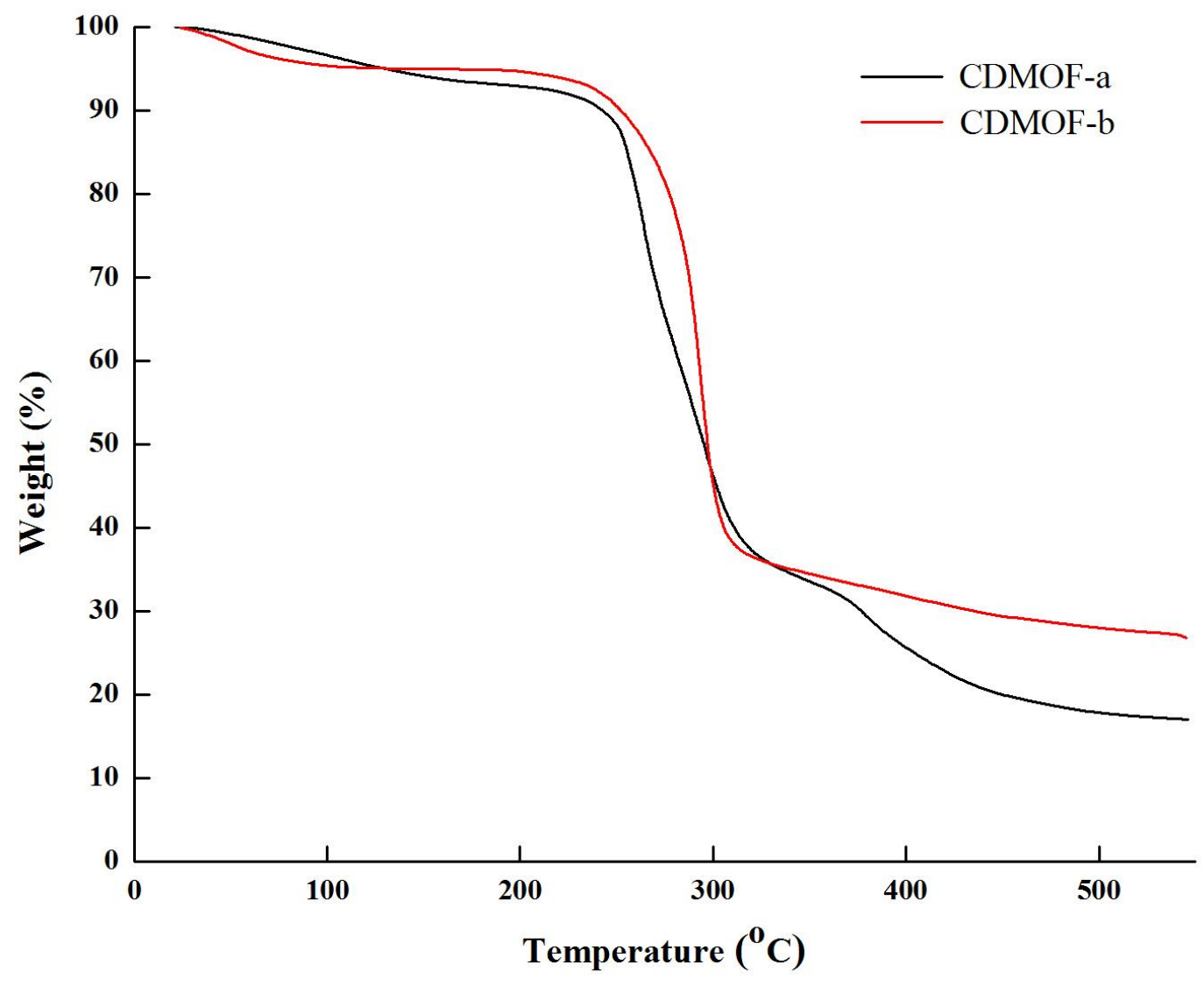


a.

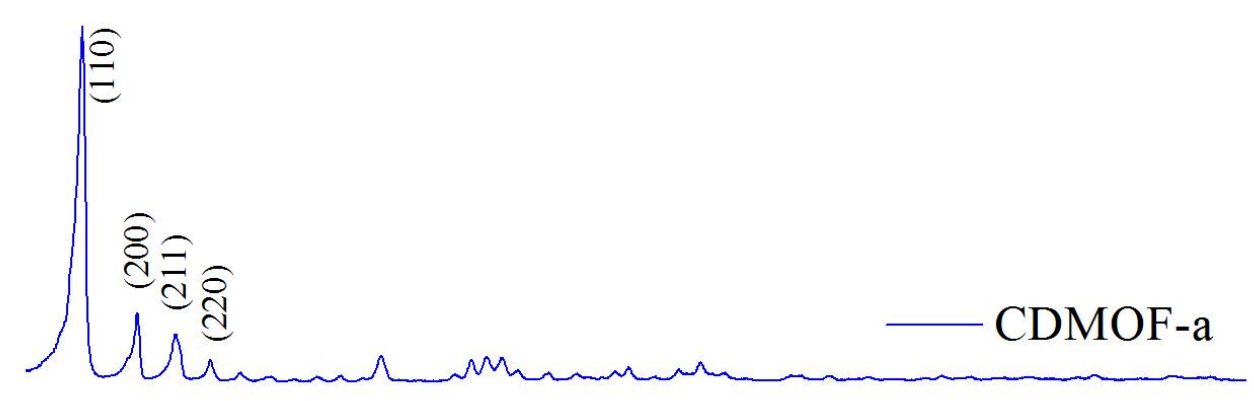

b.

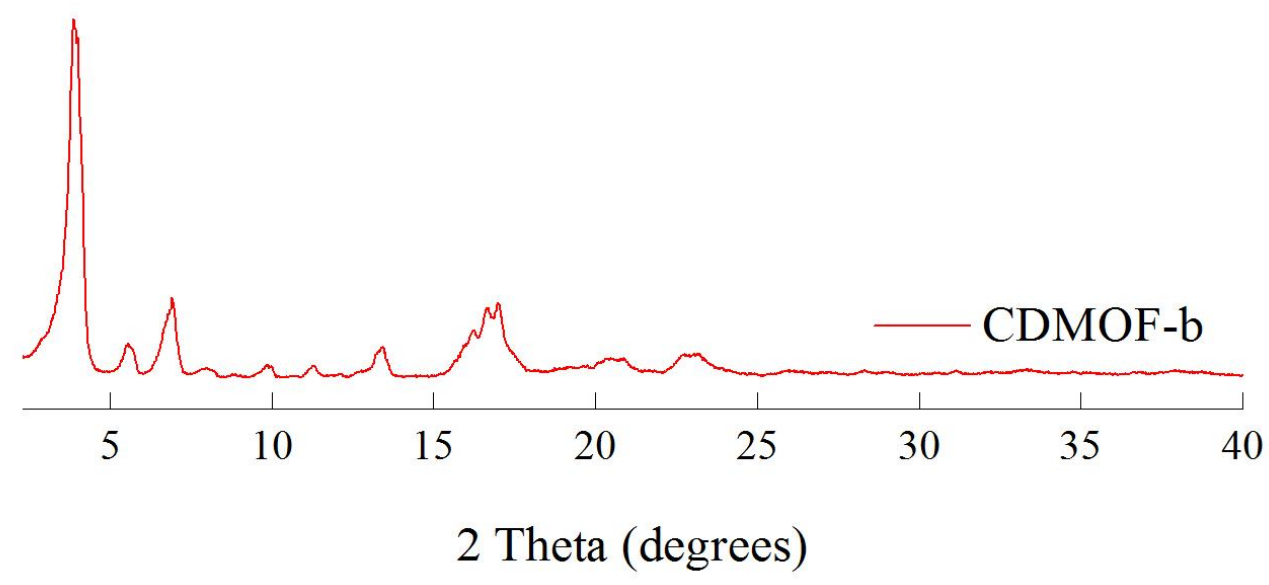

473

474

Figure 4. X-Ray diffraction of activated CDMOF-a and CDMOF-b

475

476 

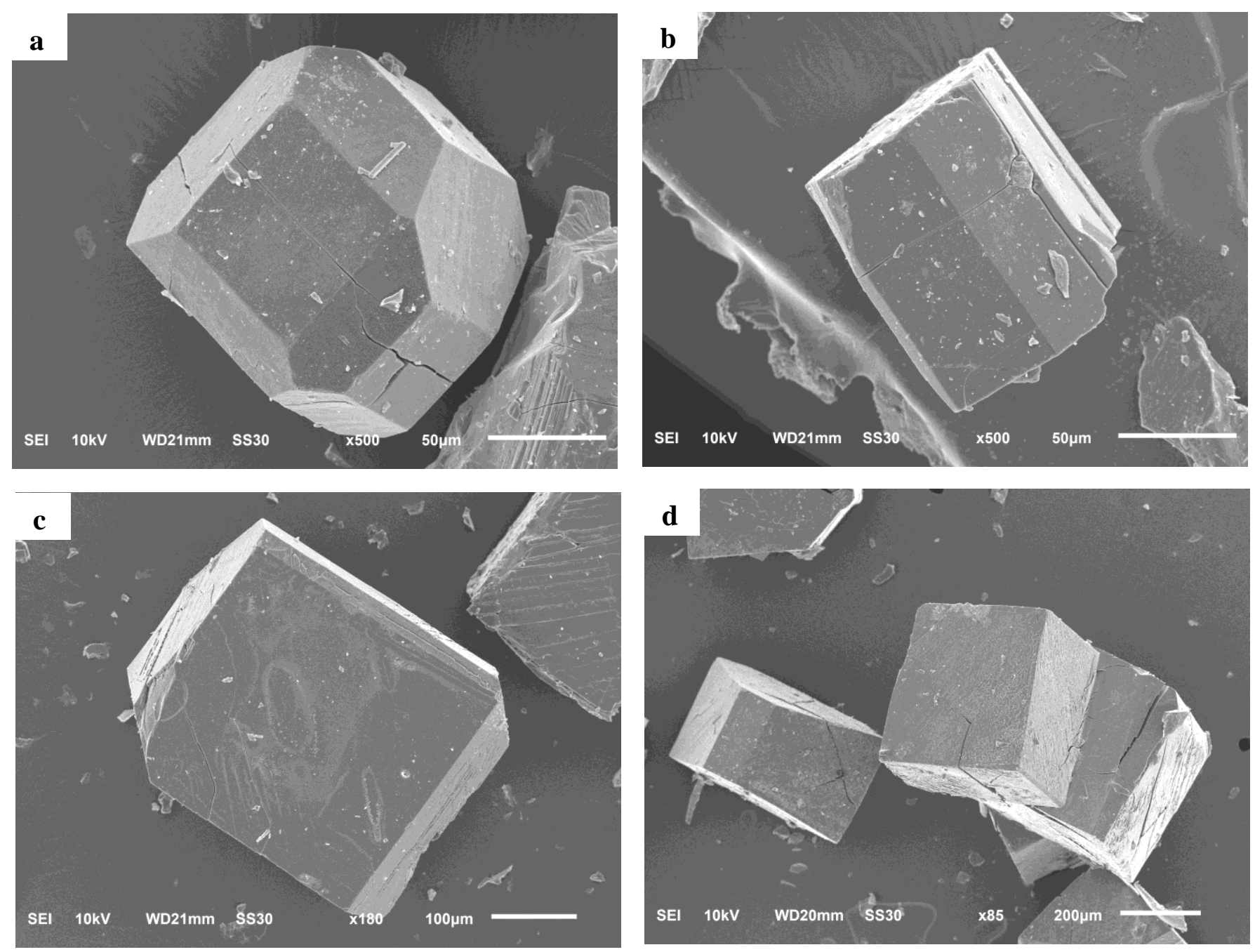

482 Figure 5. a). SEM image-I of CDMOF-a scale size $50 \mu \mathrm{m} \mathrm{b}$ ). SEM image-II of CDMOF-a scale 483 size $50 \mu \mathrm{m} \mathrm{c}$ ). SEM image-I of CDMOF-b scale size $100 \mu \mathrm{m}$. d). SEM image-II of CDMOF-b 484 scale size $200 \mu \mathrm{m}$ 


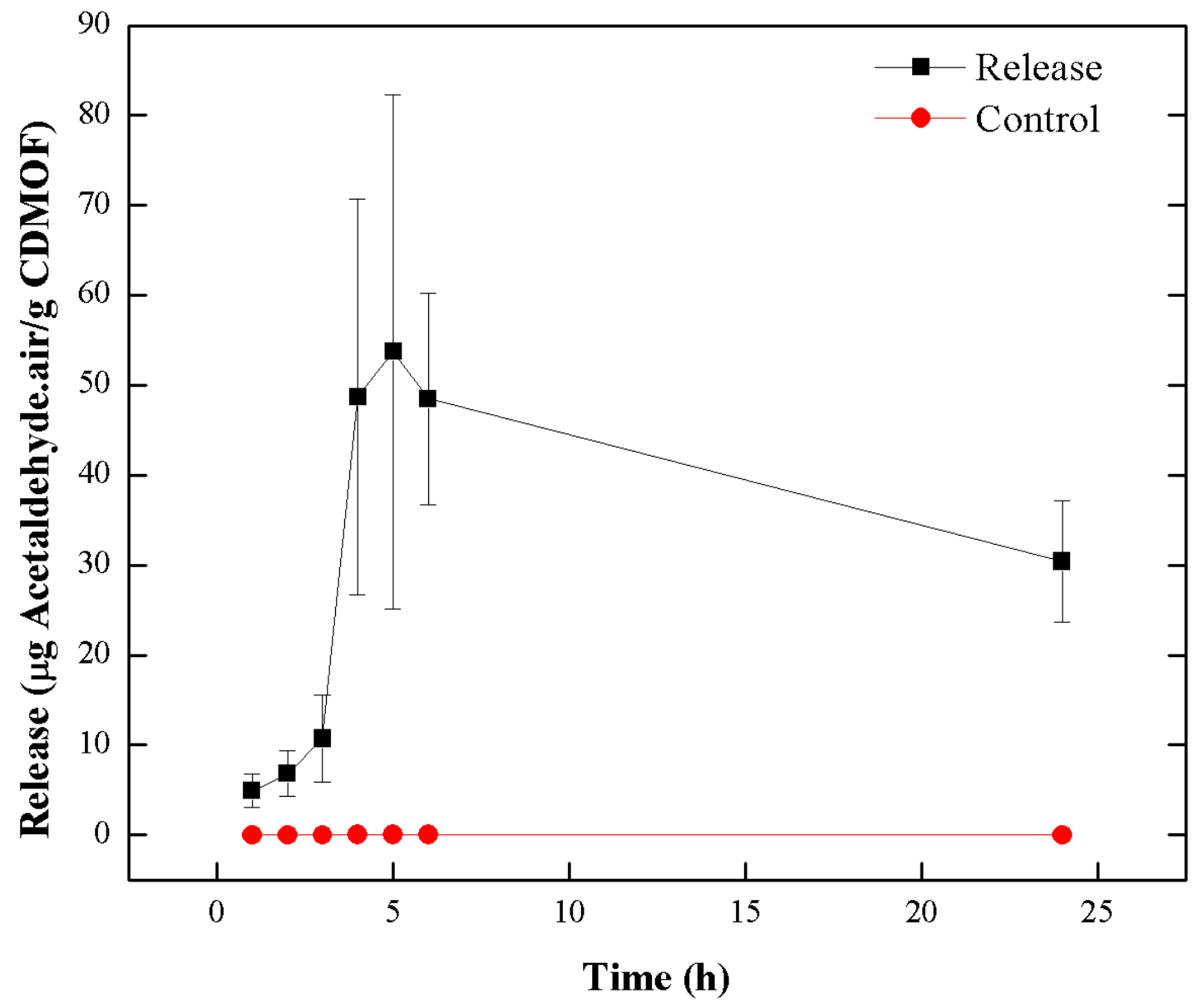

488

489

Figure 6. Release kinetics of acetaldehyde per gram of CDMOF-b

490

491

492

493

494

495

496

497 


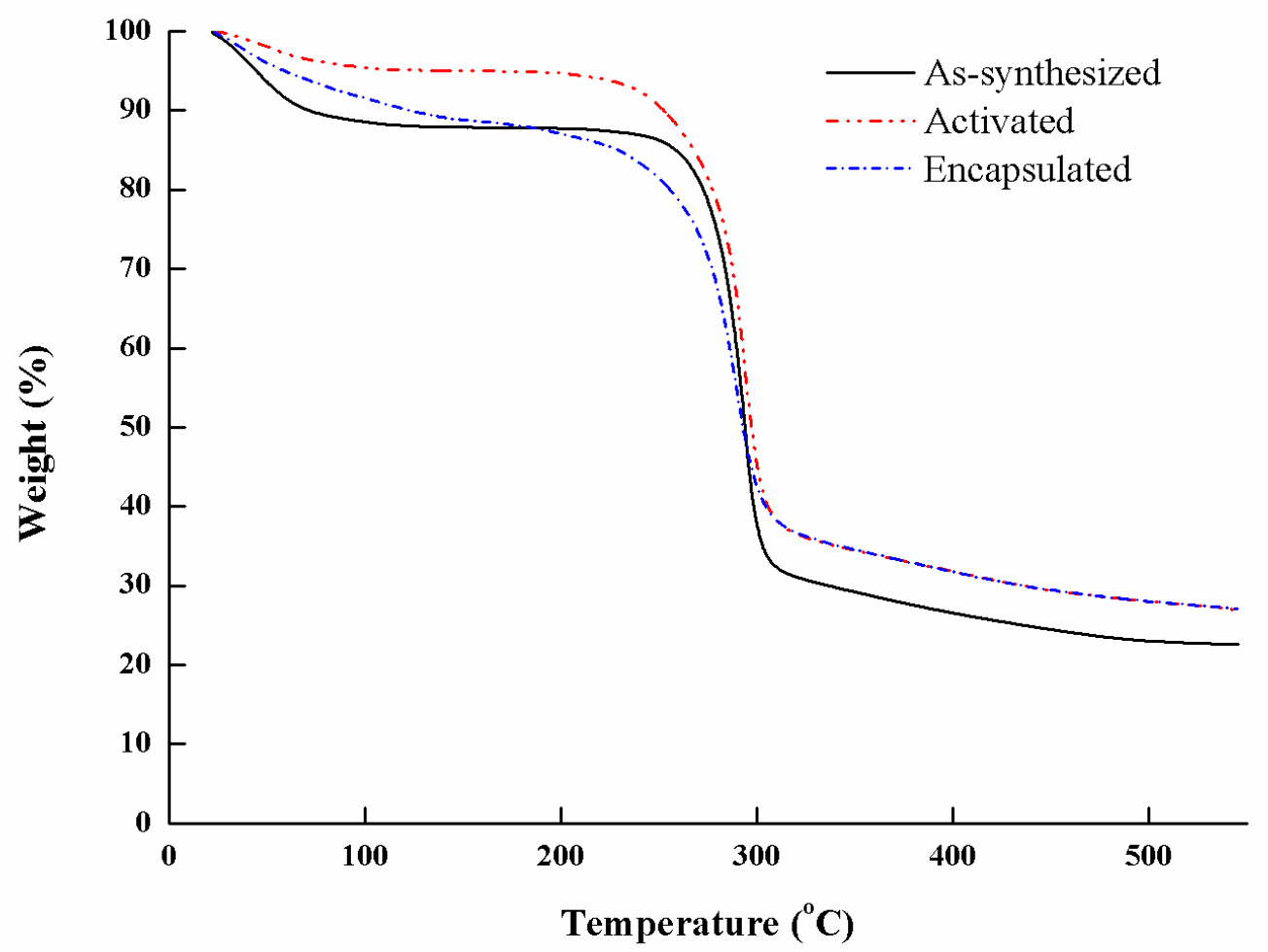

501 Figure 7. Thermo-gravimetric analysis of as-synthesized, activated, and encapsulated CDMOF-b<smiles>CC=O</smiles><smiles>CO</smiles><smiles>CC(=O)CC(C)O</smiles> 